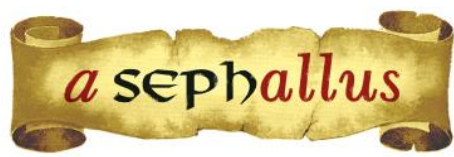

Revista aSEPHallus de Orientação Lacaniana

Núcleo Sephora de Pesquisa sobre o Moderno e o Contemporâneo

ISSN $1809-709$ X

\title{
Pagamos com o nosso corpo? 0 gozo em jogo no discurso do mestre e no capitalismo
}

\author{
Narada Miguel Lopez Vidaurre \\ Psicólogo pela Universidade Católica Boliviana "San Pablo"/UCB \\ Mestrando do Programa de Pós-graduação em Teoria Psicanalítica pela Universidade Federal do Rio de \\ Janeiro /UFRJ \\ E-mail: narada.miguel@gmail.com
}

\begin{abstract}
Andrea Martello
Professora Adjunta da Escola de Educação da Universidade Federal do Estado do Rio de Janeiro - UNIRIO Professora do Programa de Pós-graduação em Teoria Psicanalítica da Universidade Federal do Rio de Janeiro

- UFRJ

E-mail: deamartello@gmail.com
\end{abstract}

Resumo: O presente artigo faz uma reflexão sobre o corpo para a psicanálise, em relação ao que se paga ao entrar na linguagem. Para tanto o corpo será pensado a partir da metáfora extraída por Lacan (1963) em OMercador de Veneza, como uma libra de carne presa na máquina formal da linguagem. Esta metáfora nos permite estabelecer as relações do corpo com a falta e a dívida, em relação à linguagem. Posteriormente, será articulado o corpo com o discurso capitalista, enquanto este é um fato da linguagem com uma incidência muito marcada na época atual. Abordaremos então, uma serie de consequências no funcionamento e no modo de usufruirmos de nosso corpo, como por exemplo a falta de limites ou o gozo sem medida.

Palavras-chave: psicanálise; corpo; pagamento; libra de carne; gozo; discurso capitalista.

\begin{abstract}
Nous payons avec notre corps? La jouissance en jeu dans le discours du maître et dans le capitalisme

Cet article est une réflexion sur le corps de la psychanalyse en relation à ce qu'on paye pour entrer dans la langue. Le corps est pensé à partir de la métaphore extraite par Lacan (1963) de Le Marchand de Venise comme une livre de chair prise dans la machine formelle de la langue. Cette métaphore nous permet d'établir les relations de l'organisme avec le manque et la dette, en relation à la langue. Plus tard, nous articulons le corps avec le discours capitaliste, alors qu'il est un fait de la langue avec un impact très marqué sur l'époque actuelle. Nous discuterons ensuite une série de conséquences sur le fonctionnement de notre corps et dans le mode d'usufruit comme par exemple le manque de limites ou la jouissance sans mesure.
\end{abstract}

Mots-clés: psychanalyse; corps; paiement; livre de chair; jouissance; discours capitaliste.

Do we pay with our body? The jouissance at stake in the master's discourse and in capitalism The following article presents a reflection on the body for psychoanalysis in relation to what is paid to enter the language. In order to do so, the body is thought from the metaphor extracted by Lacan (1963) from The Merchant of Venice as a pound of flesh caught in the formal machine of language. This metaphor allows us to establish the relations of the body with lack and debt, in relation to the language. Later we will articulate the body with the capitalist discourse, while this is a fact of language with a very incidence in the present time. We will then approach several consequences in the working of the body and the way we enjoy it, for example lack of limits or unmeasured enjoyment.

Keywords: psychoanalysis; body; payment; pound of flesh; enjoyment; capitalism discourse. 


\section{Pagamos com o nosso corpo? \\ 0 gozo em jogo no discurso do mestre e no capitalismo}

Narada Miguel Lopez Vidaurre \& Andrea Martello

O presente trabalho visa refletir sobre o corpo para a psicanálise em relação ao que se paga ao entrar na linguagem. $O$ pagar neste caso refere-se à metáfora de como a linguagem constitui o corpo e produz uma perda, isto é, alguma coisa se entrega em troca ou se deixa para trás no que tange ao advento do sujeito. Avançamos um passo a mais nesta questão e também visamos pensar como o discurso capitalista articula o corpo e o sujeito, já que os discursos são fatos da linguagem que afetam o sujeito e produzem gozo. Portanto, este discurso do capitalismo tem destaque e representa uma incidência particular da presente época na constituição e no funcionamento da subjetividade dos seres falantes e, por conseguinte, do corpo. Toda esta reflexão nos servirá para abordarmos a questão de saber sobre o que se paga do corpo para entrar na lógica da linguagem, e, mais ainda, o que se paga para entrar no âmbito do discurso capitalista.

Para definir de que corpo trataremos, tomaremos como referência o seminário 10 de Lacan (1962-1963) A angústia, a partir do qual podemos recorrer à formulação do corpo como uma libra de carne presa na máquina formal da linguagem. Esta concepção localiza a constituição do corpo através da metáfora extraída de $O$ mercador de Veneza, de Shakespeare, no qual, em um momento determinado o pagamento da dívida deveria ser realizado com uma libra de carne. Lacan toma esta metáfora para ilustrar a relação do corpo com a linguagem constituída a partir da dívida simbólica. Devemos lembrar que a lógica da dívida está baseada na falta, seja do lado daquele que deve, seja do lado do credor. Resumiremos brevemente a história para vermos do que se trata. A obra começa com Bassanio, um nobre italiano sem recursos, desejando cortejar uma rica herdeira, Porcia. Para isto, pede emprestados 3000 ducados a seu amigo Antônio, um mercador veneziano, que tem todo o seu dinheiro em barcos no estrangeiro e, por isso, tem que pedir empréstimo a um usurário judeu, Shylock. Este último aceita emprestar a quantia, mas com a seguinte condição: se a dívida não for quitada, deverá ser paga com o próprio corpo. Devido a uma série de eventos, o mercador não pode pagar a dívida, portanto, Shylock reclama o cumprimento do acordo. Exige uma libra de carne próxima do coração, mas apenas poderia ser carne e não poderia derramar nem um pouco de sangue. Esta é a parte da história que interessa para ilustrar o que se paga para entrar na linguagem.

A ideia da libra de carne como pagamento da dívida permite localizar diversas nuances na constituição do corpo. Como sabemos, a linguagem é uma coisa que nos antecede, que já está aí desde $o$ início. A linguagem nos afeta, nos demanda um lugar a ser ocupado, nos impõe entregar alguma coisa, se baseia na lógica do "Che vuoi? - Que queres?" -, pergunta que lança o sujeito no ponto da angústia uma vez que ele não saiba responde-la. Veremos adiante como a angústia revela o que a fantasia esconde, a saber, que no advento do sujeito um corte se presentifica como perda. Isto se exemplifica através de uma frase de Lacan do Seminário 10: "É teu coração o que eu quero, 
mais nada" (Lacan, 1962-1963, p. 238). Proposição metafórica amorosa que anuncia o desejo de obter o que geralmente em linguagem comum chamaríamos a essência, o ser ou amor do outro, uma parte vital de suma importância. Esta frase abre para múltiplas questões, mas nos centraremos na vertente do enunciado que representa a demanda do Outro da linguagem, que requer uma parte valorizada nossa, nosso coração e que não é outra coisa que a libra de carne que nos fala a metáfora.

A linguagem afeta o organismo nos diferentes níveis da experiência corporal. Uma vez afetado pela linguagem, o corpo passa a se submeter e a funcionar de maneira que não pode ser revertida. Os órgãos e as diferentes partes do corpo passam a ter uma função metafórica, ou seja, passam a ser afetados pela linguagem, comandados e marcados pelo significante. 0 corpo que se constitui então é o corpo das zonas erógenas (Freud, 1905), fonte das pulsões e dos objetos parciais - anal, oral, fálico -, aos quais posteriormente Lacan (1962-1963) acrescentará os objetos voz e olhar. São objetos parciais uma vez que não podem ser integrados pelo sujeito, são o que do corpo não alcança a transcendência do significante. A conformação desses objetos está feita em relação à experiência da angústia, onde algo se perde e o sujeito deve advir para instalar a função significante. A angústia é o operador que permite a separação, pois tem que ser franqueada para que o sujeito do desejo possa advir.

A vivência da castração simbólica experimentada na caducidade dos objetos traz como resultado a constituição dos orifícios naturais com a qualidade de borda. A borda se constitui através da perda do objeto, instaurando a dimensão do objeto perdido. É preciso a perda dos objetos (placenta, seio, fezes, pênis) para que se instaure o corpo como bordas que permitam o acesso ao campo do Outro. Estas zonas representam o lugar por onde se operam a alienação e a separação, por serem as zonas de intercâmbio com o Outro. A separação resulta da extração do objeto e instaura a divisão entre o sujeito e o objeto. No tempo anterior, o da alienação, sujeito e objeto estavam indiferenciados. As bordas corporais representam o lugar suscetível da intervenção do Outro da linguagem. Mas estas zonas vão ter, como veremos mais adiante, um papel particular no funcionamento do corpo. Principalmente a partir do discurso do capitalismo, que reintroduzirá no âmbito do objeto perdido os gadgets, os objetos de consumo.

O significante é o que estrutura nosso aparelho psíquico. Ele designa o modo de conhecer os objetos, pois cria a diferença entre um objeto e outro. Assim como também a relação do corpo com eles, já que nomear o objeto também permite sua utilização e, finalmente, tudo isto institui a relação do corpo com o mundo dos objetos e das palavras. Mas o mais importante a ressaltar das consequências desta constituição do corpo é que ela também representa a passagem de um gozo indiscernível a um gozo limitado e extraído pela ação significante. Portanto, a linguagem limita o funcionamento corporal, produzindo uma regulação do gozo do corpo a partir da zona erógena.

Uma das consequências da incidência da linguagem é a produção de um resto de literalidade, a queda de um objeto, que justamente é o objeto $a$, como peça destacada pelo encontro com a linguagem. $\mathrm{O}$ objeto $\mathrm{a}$ aparece como resto, mas ele também representa a parte que sobrevive ao 
encontro com a linguagem. Trata-se de um resto irredutível que falta em seu lugar e a partir desse momento é que ele tem sua função. Para entender esta dimensão, nos serviremos do esquema da divisão de Lacan (1962-1963), que aparece no seminário 10, A angústia. Ao longo do seminário, são desenvolvidos três esquemas com diferentes nuances acerca da constituição do sujeito no campo do Outro. Trabalharemos apenas o terceiro, pois é o que traz os elementos que nos interessam.

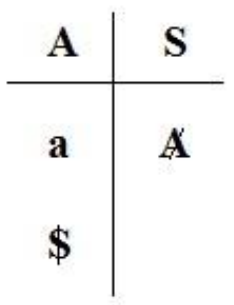

O esquema divide o campo do Outro (A) e o campo do sujeito (S), aplicando a estes uma lógica aritmética simples de divisão. Nele, temos que o sujeito se constituirá no campo do Outro (da esquerda) deixando como restos desta operação de alienação um real irredutível (a) e, por fim, o sujeito do desejo (\$), circunscrevendo um movimento que vai da angustia ao desejo. No lado direito se inscreve como resultante do movimento de alienação do sujeito ao Outro (A) a inscrição do Outro como barrado (A), resposta para o que se coloca com a pergunta "Che vuor?", "Que queres?", que anuncia para o sujeito a dimensão do desejo ainda que no ponto da angústia. O esquema apresentado traduz a situação em que num primeiro momento a angústia surge para o sujeito como afeto que sinaliza a presença do real irredutível que se opõem ao significante, e que, apesar de sua função opaca, é o que deve orientar o psicanalista. A angústia é o sinal de um real irredutível para o sujeito, sinal de uma divisão por vir que inclui uma perda. A dimensão do objeto $a$, colocada aqui como primeiro termo no encontro com o Outro, presentifica a angústia como momento anterior à perda dos objetos parciais que constituem o corpo como borda. Por isso Lacan afirma que "a angustia não é sem objeto" (Lacan, 1962-1963, p. 178). O momento da angustia é um momento em que ainda não se configurou a separação entre o sujeito e o campo do Outro ainda que já se anuncie a heterogeneidade, a divisão de seus campos. A angustia sinaliza o próprio lugar de corte:

$$
\$=\frac{a}{S}
$$

Esta última inscrição traduz a operação que define o sujeito do desejo como o equivalente ao real irredutível (a) que resta à significação pretendida (S). Através da análise, o sujeito do desejo emerge ciente de que sua inscrição na linguagem implica uma dimensão de perda de gozo que o 
castra no corpo, ainda que Ihe ofereça o acesso à sua significação. A metáfora da libra de carne presa à máquina formal da linguagem - enquanto dívida simbólica em que o sujeito empenha seu próprio corpo, seu próprio coração - fica desta forma explicitada. É o preço a pagar para se introduzir na linguagem.

\section{O discurso do capitalismo e o mais-gozar}

No seminário 16, De um Outro ao outro, Lacan (1968-1969) caracteriza o objeto a como mais-de-gozar. Delimitaremos brevemente este conceito para podermos entender alguns enunciados posteriores. Esta ideia foi tomada da teoria marxista do conceito de mais-valia. Tomaremos este conceito tão complexo apenas no que nos auxilia: a referência ao valor que o trabalhador produz acima do valor da sua força de trabalho. Isso quer dizer que há um ganho suplementar produzido pelo mesmo trabalho. A analogia com o conceito marxista é feita a partir de um ganho que se produz no curso do trabalho, em nosso caso, o ganho que se produz a partir do discurso, da fala. O que se perde em termos de objeto, de corpo, se ganha em termos de linguagem. Como sabemos, "desde o momento em que o mercado define como mercadoria um objeto qualquer do trabalho humano, esse objeto carrega em si algo da mais-valia. Assim, o mais-de-gozar é aquilo que permito isolar a função do objeto $d^{\prime \prime}$ (Lacan, 1968-1969, p. 19). A função do objeto a como mais-de-gozar está baseada no fato de este objeto, ao se instaurar como objeto perdido, permite capturar o gozo, recuperar algo do gozo perdido. O mais peculiar é que, como afirmamos anteriormente, a linguagem produz um esvaziamento do gozo do corpo. O conceito de mais-de-gozar como recuperação do gozo só pode ser estabelecido a partir da perda. Isto quer dizer que, logicamente, para haver uma recuperação é preciso acontecer uma perda anterior. Aqui podemos localizar uma das funções do objeto a, como condensador de gozo.

Anteriormente nós falamos da constituição do corpo e das zonas erógenas como orifícios com qualidade de borda. Mas agora também podemos entender esses lugares como lugares onde se pode localizar o gozo. O corpo empresta esse contorno para albergar o gozo e poder produzir o mais-de-gozar a partir dos objetos parciais.

Pelo início do funcionamento do organismo, constata-se que o objeto pode assumir a imagem das entidades evanescentes cuja lista já forneci, que vão do seio à evacuação e da voz ao olhar. Essas são outras tantas fabricações do discurso da renúncia ao gozo. O que impulsiona essa fabricação é isto: em torno delas pode produzir-se o mais-de-gozar. (Lacan, 1968-1969, p. 22)

De início, supomos que um corpo é corpo de linguagem, submetido às leis desta e aos discursos imperantes da época. A partir deste ponto, e referindo-nos à estrutura dos quatro discursos proposta por Lacan em 1969, articularemos o discurso capitalista formalizado por ele posteriormente. 
Os discursos tentam dar conta das diferentes formas de laço social e representam distintas posições frente à impossibilidade da relação sexual e do gozo. Os discursos são um ordenamento a partir do significante, mediante o qual se estrutura o saber e as diferentes posições subjetivas como modo de produção de gozo.

A estruturação dos discursos se baseia na relação de quatro elementos ou posições, por isto mesmo as possibilidades não são infinitas, senão apenas quatro: o discurso do mestre, o discurso da histeria, o discurso universitário e o discurso do analista. Lacan (1968-1969) estabelece quatro lugares (agente, verdade, outro, produção), com quatro funções em relação às quais se situa o sujeito: o significante inaugural $\left(S_{1}\right)$, o saber $\left(S_{2}\right)$, o sujeito $(\$)$ e o objeto $a$.

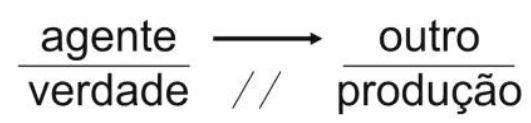

Aquilo que encontramos na estrutura do discurso do mestre é a operação de recalque que funda o sujeito na linguagem, que instaura o significante $\left(S_{1}\right)$ no lugar de agente a partir de um corte entre o sujeito que opera do lugar da verdade, e o corpo como lugar do gozo (produção), as bordas corporais. 0 discurso do mestre trata de uma mortificação essencial do corpo para o advento do sujeito na linguagem.

$$
\frac{S 1}{\$} \rightarrow \frac{S 2}{a}
$$

Os outros discursos se produzirão a partir de um quarto de giro em relação a este, alterando o lugar do agente: quando ocupado pelo sujeito barrado, temos o discurso da histeria; quando ocupado pelo saber, temos o discurso do universitário; e quando ocupado pelo objeto $a$, o discurso do analista. Posteriormente, no Congresso de Milão, Lacan (1972) adicionará o discurso capitalista, anunciado uma única vez. O matema deste discurso é justamente o que nos interessa no presente artigo. $O$ interessante é que tal discurso se produz a partir de uma distorção do discurso do mestre, e não através dos quartos de giro. É a lógica do discurso do mestre que o discurso capitalista subverte, suspende, distorce. O discurso capitalista é o que denominamos como "falso discurso" em virtude de seu particular funcionamento.

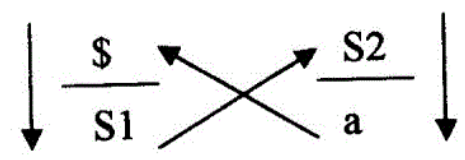


Os elementos, conforme se apresentam, são semelhantes ao discurso do mestre. Há, porém, uma inversão, uma torção entre o lugar do sujeito e do significante mestre. O sujeito sai da posição da verdade, que o garantia a partir do recalque, para se colocar como agente. Esse lugar cria a aparência de um falso mestre, típica do capitalismo, que na sociedade de consumo de massa faz parecer que é o sujeito singular que escolhe o que consumir quando ele não mais é do que determinado pelos significantes que orientam sua escolha. Isso se traduz pela relação que o sujeito mantém com o $S_{1}$ : é de uma alienação a este que ainda se trata, e com a inversão, é o significante mestre que resta velado operando a partir do lugar da verdade. É o $S_{1}$ e não o sujeito que organiza o campo do saber $\left(\mathrm{S}_{2}\right)$, resultando disso o destacamento de um real irredutível (a). O vetor designado por a $\rightarrow$ \$ seria algo impensado nos esquemas de 1969 que tratam da fundação do discurso do mestre. É neste ponto que se consuma a questão da suspensão do recalque, suspensão do corte em relação ao campo do Outro através da dimensão do objeto perdido. Assim, desaparece a dupla barra que separava os termos do sujeito e do objeto a no discurso do mestre, e o que aparece com a suspensão do recalque é uma relação direta com o objeto de gozo. Surge, desta forma, um sujeito comandado pelo discurso e sem nenhuma determinação além de consumir.

O dilema de toda esta situação que temos trazido até o momento é que o pagamento está baseado no intercâmbio a partir da falta, sendo que o mais interessante é que o nosso próprio corpo é a única coisa que nós realmente podemos ter para trocar. $E$ isto novamente tem consequências. Leva-nos a formular algumas questões centrais: qual é preço que pagamos com nosso corpo nesta operação do discurso capitalista? Quais são as consequências deste pagamento? Qual é a particularidade que o discurso capitalista traz para o corpo?

Podemos pensar que, se Lacan (1972) propôs o discurso capitalista, era porque os outros discursos não davam conta do funcionamento da relação do ser falante na atualidade. Estamos em uma época em que temos que pagar por tudo, e se há algum discurso que articula a lógica do pagamento é justamente o discurso capitalista. O mais curioso de tudo isto é que desconhecemos que também pagamos e entregamos parte de nosso corpo ao serviço deste discurso. Por isto mesmo, o que aparece como anverso de nossa sociedade atual é uma ampla oferta de objetos de consumo à serviço do discurso capitalista, que afeta o modo como usamos e usufruímos de nosso corpo. Este está baseado em uma nova forma de laço social, que paradoxalmente dissolve o laço em si mesmo devido à tentativa de relação direta com o objeto. É um discurso que está destinado a explodir. Em relação à torção operada pelo discurso do capitalismo, Lacan nos diz "é suficiente para que isso ande sobre rodas, não pode ir melhor, mas justamente corre rápido demais, isso se consuma, se consuma tão bem que se consome"2 (Lacan, 1972, p. 13, tradução nossa).

Como sabemos, todo discurso é semblante, e o discurso capitalista é um semblante que parece funcionar muito bem. Mas servir-nos deste discurso tem um preço. Por um lado, como falamos anteriormente, uma das consequências de "pagar a libra de carne" é que também se produz uma regulação do corpo através do corte pelo significante, isto quer dizer que este é o preço a ser 
pago para certo ordenamento pulsional. Este é o ponto de angústia que o discurso do capitalismo visa camuflar ao oferecer objetos compensatórios. Por outro lado, o discurso capitalista, que tudo promete, está baseado em uma falta de determinação ou de limites, exibindo desta forma uma suspensão da necessidade do recalque. Ele promete a satisfação de todos os desejos. Vários dos sintomas que afetam o corpo na contemporaneidade guardam relação com a falta de limites (anorexia, obesidade, adição), atrelados a um excesso de gozo. Portanto, podemos pensar que umas das consequências deste discurso no corpo é este tipo de gozo voraz que aparece sem nenhum tipo de regulação.

Trata-se então de um imperativo de gozo consumista forjado na malha do objeto a como mais-de-gozar. O discurso capitalista oferece diversos objetos para a satisfação pulsional. Estamos ante a tentativa de oferta de um catálogo sem limites dos diferentes objetos - oral, anal, invocante ou escópico - que visam a produção de gozo que não leva em conta a perda. Por exemplo, atualmente, com a tecnologia, a distância não é mais um problema para a comunicação, mas paradoxalmente quanto mais possibilidades de estar conectados temos mais pessoas impossibilitadas de estabelecer relação como o outro. Justamente o que aparece em questão nestes casos é que desconhecemos o preço a pagar pelo consumo destes objetos. Isto quer dizer que o fato de não oferecer limites precisos faz como que se corra o risco de acabar devorado pelo gozo, alienado novamente numa relação com o grande Outro, sem separação, sem extração da dimensão do objeto perdido e consequentemente do sujeito. Este consumo do corpo em detrimento da dimensão do sujeito é que vemos ocorrer hoje.

\section{Para concluir}

E como reflexão final frente a este modo de articulação do significante que o discurso capitalista difunde, é de grande importância mencionar que ainda que a linguagem esteja presente para todos, não afeta ou incide do mesmo jeito sobre todos os sujeitos. Lacan (1955) em "A Carta roubada" nos mostra que o significante marca o sujeito de modos diferentes, segundo sua relação ou posição frente a eles. Também ressalta que na linguagem o significante obedece a leis de exclusão nas quais nem tudo é possível, portanto, é importante a construção da cadeia significante que determinou cada sujeito. Ao modo de um breve apontamento, diremos que é de suma importância marcar que não se pode pensar a dimensão do sujeito sem visar os elementos que o constroem e como estes incidiram nele. Por esta razão, a lógica da intervenção analítica está baseada na redução do significante ao sem-sentido, para assim encontrar aqueles significantes que determinaram o sujeito em seu modo de gozo.

O subjetivo é algo que encontramos no real... o subjetivo supõe que temos em frente de nós um sujeito que é capaz de se servir do significante como tal... e de se servir do jogo significante, não para significar algo, senão precisamente para nos enganar 
sobre o que há a significar...se servir do fato que o significante é outra coisa que a significação, para apresentar-nos um significante enganoso. (Lacan, 1972, p. 11)

Podemos observar que a sociedade atual oferece toda uma série de nomenclaturas acerca dos sintomas psicopatológicos que não deixam de ser significantes, oferecendo um lugar no Outro para o sujeito. Este fato nos leva a pensar sobre o porquê que de todos os significantes que o sujeito poderia tomar no campo do Outro, ele escolhe esses significantes. E nos surge a hipótese de que esses significantes fornecidos pelo discurso psicopatológico da psiquiatria representam aqueles que são exatamente os que têm a ver com algum padecimento subjetivo, que estão ancorados num ponto de gozo do corpo. 0 que chama a atenção nas nomenclaturas psiquiátricas as quais o sujeito se reduz hoje em dia, é que junto delas há uma prescrição medicamentosa, ou mesmo a ideia de uma determinação genética ainda por ser manipulada, mas sempre algo que promete mexer no corpo de modo a garantir que nenhuma perda seja sentida. Ou, pelo menos, a promessa de algo que possa compensar a perda sofrida. Do objeto perdido ao objeto mais-gozar, essa travessia não parece mais ser empreendida pelo sujeito, mas pelos significantes mestres e objetos ofertados pela indústria farmacêutica.

Um exemplo dos mais simples para aproximarmos desta questão, e a partir do que encontramos com facilidade na clínica atual, são as diferentes reclamações dos pacientes sobre os seus padecimentos no corpo, sobre aquilo que em aparência não funciona e que dispõe de um nome na clínica médica. Mas o mais interessante é que muitas destas pessoas rapidamente se apresentam pelo seu sintoma, por exemplo "eu sou Maria e sou depressiva", ou justificativas do tipo "Eu não consigo trabalhar porque sou agorafóbico". É importante ressaltar que "a palavra "ser" não tem sentido fora da linguagem" (Lacan, 1972, p. 3). Portanto, podemos pensar que todos estes tipos de identificações estão ancorados fortemente no gozo que, como vimos, é um efeito da linguagem. É importante ressaltar como o campo da psiquiatria, ao mesmo tempo que oferece uma nomenclatura psicopatológica que serve ao subjetivismo significante, oferece a substancia química que incide sobre o ponto nomeado. Poderíamos pensar que o sujeito tem um ganho através da utilização deste tipo de significante, e este ganho é o que denominamos mais-de-gozar. Mas, para usufruir deste modo de gozo, há que se pagar com o corpo mediante à redução de sua experiência subjetiva ao sintoma desenhado pela psiquiatria, o que leva, cada vez mais, a uma medicalização excessiva da vida.

\section{Notas:}

${ }^{1}$ Este trabalho foi apresentado no Simpósio do ISEPOL, em 01/10/2016, realizado nos dias 30/09 e 01/10/2016, no Rio de Janeiro. Foi apresentado na mesa simultânea "Supervalorização da saúde: intolerâncias alimentares e outros transtornos do corpo" e contou com a orientação da Profa. Dra. Tania Coelho dos Santos. Ele se insere na pesquisa de mestrado "El cuerpo como una libra de carne 
atrapada en la maquina formal del lenguaje", financiada pela CAPES, no PPGTP/UFRJ, orientada pela Profa. Dra. Anna Carolina Lo Bianco.

${ }^{2}$ No original: "es suficiente para que esto marche sobre ruedas, no puede marchar mejor, pero justamente marcha demasiado rápido, se consuma, se consuma tan bien que se consume" (Lacan, 1972, p. 13).

\section{Referências Bibliográficas}

Freud, S. (1979). Tres ensayos de una teoría sexual y Otras obras. Obras completas (Vol. VII). Buenos Aires: Amorrortu (Texto originalmente publicado em 1905).

Lacan, J. (1998). O seminário sobre a carta roubada. Escritos. Rio de Janeiro: Jorge Zahar (Texto originalmente publicado em 1955).

Lacan, J. (2010). O seminário, livro 10: a angústia. Rio de Janeiro: Jorge Zahar (Texto originalmente publicado em 1962-1963).

Lacan, J. (1999). O seminário, livro 11: os quatro conceitos fundamentais da psicanálise. Rio de Janeiro: Jorge Zahar (Texto originalmente publicado em 1964).

Lacan, J. (2008). O seminário, livro 16: de um Outro ao outro. Rio de Janeiro: Jorge Zahar (Texto originalmente publicado em 1968-1969).

Lacan, J. (2008). O seminário, livro 17: o avesso da psicanálise. Rio de Janeiro: Jorge Zahar (Texto originalmente publicado em 1969-1970).

Lacan, J. (1972). Del discurso psicoanalítico. In Mater, O. M. (Trad.). Recuperado de http://www.elsigma.com/historia-viva/traduccion-de-la-conferencia-de-lacan-en-milan-del-12-demayo-de-1972/9506.

Citacão/Citation: Vidaurre, N. M. L. \& Martello, A. (mai. a out. 2016). Pagamos com o nosso corpo? O gozo em jogo no discurso do mestre e no capitalismo. Pagamos com o nosso corpo? O gozo em jogo no discurso do mestre e no capitalismo. Revista aSEPHallus de Orientação Lacaniana, 11(22), 60-69. Disponível em www.isepol.com/asephallus. doi: 10.17852/1809-709x.2019v12n23p60-69.

Editor do artigo: Tania Coelho dos Santos.

Recebido/Received: 20/12/2016 / 12/20/2016.

Aceito/Accepted: 07/01/2017 / 01/07/2017.

Copyright: (C) 2013 Associação Núcleo Sephora de Pesquisa sobre o moderno e o contemporâneo. Este é um artigo de livre acesso, que permite uso irrestrito, distribuição e reprodução em qualquer meio, desde que o autor e a fonte sejam citados/This is an open-access article, which permites unrestricted use, distribution, and reproduction in any medium, provided the author and source are credited. 